\title{
LA ESTRATEGIA DE ENGAGEMENT DE NETFLIX ESPAÑA EN TWITTER
}

The engagement strategy of Netflix Spain in Twitter

\section{Erika Fernández-Gómez y Juan Martín-Quevedo}

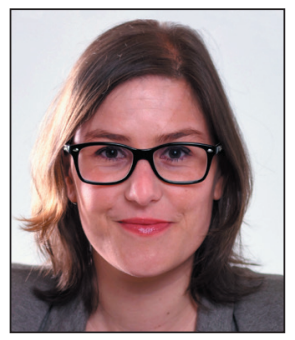

Erika Fernández-Gómez es profesora adjunta en la Universidad Internacional de la Rioja (UNIR) desde 2010 donde imparte docencia en el área de Comunicación. Acreditada por la Aneca como profesor contratado doctor, cuenta con un sexenio de investigación (Cneai). Es miembro del grupo de investigación Comunicación y Sociedad Digital (Coysodi) de la UNIR y sus principales líneas de investigación son televisión, publicidad, redes sociales, comunicación de salud y audiencia infantil y juvenil.

https://orcid.org/0000-0002-7088-1814

erika.fernandez@unir.net

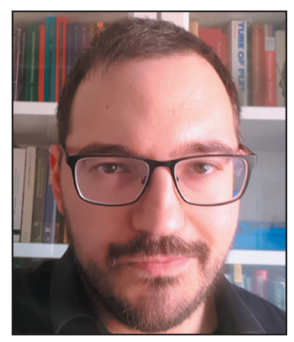

Juan Martín-Quevedo es profesor ayudante en la Universidad Internacional de la Rioja (UNIR) desde 2011, donde imparte docencia en el área de Comunicación. Acreditado por la Aneca como profesor contratado doctor. Es miembro del grupo de investigación Comunicación y Sociedad Digital (Coysodi) de la UNIR y sus principales líneas de investigación son: televisión, radio y redes sociales.

https://orcid.org/0000-0003-1005-0469

juan.martin@unir.net

Universidad Internacional de La Rioja (UNIR) Facultad de Empresa y Comunicación Av. de la Paz, 137. 26006 Logroño, España

\section{Resumen}

Esta investigación analiza cómo la plataforma de televisión en streaming Netflix consigue generar comunidad en la red social Twitter. A través de un análisis de contenido ( $\mathrm{N}=1.048$ tweets, $\mathrm{n}=100$ tweets) se responde a las características que presentan aquellos mensajes que más conversación generan, más se comparten y más gustan. Los resultados reflejan lo que la audiencia social valora de una marca audiovisual para relacionarse con la misma. Se concluye que contar con una estrategia de creación propia, promocionar e informar sobre series y emplear el lenguaje propio de la red-como el hashtag acompañado de recursos visuales- incrementa la participación de los seguidores. Además, plantear preguntas para estimular la participación, recurrir al humor o al suspense ayuda en este cometido.

\section{Palabras clave}

Series de televisión; Streaming; Engagement; Viralidad; Redes sociales; Medios sociales; Twitter; Netflix.

\section{Abstract}

This paper analyses how the streaming television platform Netflix creates a community in Twitter. Through a content analysis ( $N=1,048$ tweets, $n=100$ tweets) we explore the characteristics of the messages with more answers, more likes and more retweets. Results allow to ascertain what the audience finds more relatable in a TV brand. Conclusions show that having a creative strategy, promote and inform about series, and using the social media language, like hashtags and visual resources, contribute to the follower's participation. Asking questions looking for participations or using humour or intrigue also helps towards this objective.

\section{Keywords}

Television series; Engagement; Streaming; Viral; Social media; Twitter; Netflix.

Fernández-Gómez, Erika; Martín-Quevedo, Juan (2018). “La estrategia de engagement de Netflix España en Twitter”. El profesional de la información, v. 27, n. 6, pp. 1292-1302. 


\section{Introducción}

\subsection{Escenario de consumo audiovisual}

La televisión convencional sigue siendo la pantalla principal en España (Barlovento Comunicación, 2017a, p. 4), si bien el consumo en 2016 -tanto online como diferido- descendió por cuarto año consecutivo al pasar de 246 minutos diarios por persona de media en 2012 -año de máximo consumo- a 233 en 2016.

En este mismo período se alcanzó un récord en el visionado de televisión de pago con un consumo del $20,4 \%$ de los hogares y una tendencia al alza (Barlovento Comunicación, 2017c, p. 1). El 35\% de los individuos de 4 ó más años ${ }^{1}$ están abonados o reciben alguna de las modalidades de televisión de pago (Barlovento Comunicación, 2017c; Samaniego, 2017). Este incremento se debe a la llegada a España de operadores mundiales de streaming como Netflix, HBO y Amazon Prime. Por el contrario, el consumo de vídeo online crece año a año: 67 minutos en 2017, y se calcula que seguirá ascendiendo 9 minutos diarios cada año hasta 2020 (Zenith, 2018).

Según el Panel de Hogares del 20 trimestre de 2017 de la Comisión Nacional de los Mercados y la Competencia (CNMC), uno de cada cuatro hogares tiene una suscripción a una plataforma de pago para ver contenidos audiovisuales online. Movistar+ es la más utilizada (12,6\%), seguida de Netflix $(7,3 \%)$-la que mayor crecimiento ha experimentado- y $H B O$ (2,6\%). Además, en el caso de plataformas como Netflix, el número de usuarios puede ser mayor ya que es una práctica habitual que varias personas utilicen una misma cuenta. Este estudio también evidencia que casi cuatro de cada diez españoles vieron contenidos audiovisuales por internet al menos una vez a la semana. A pesar de ello, el $77 \%$ de los hogares con acceso a la Red no utiliza plataformas de pago audiovisuales.

\section{El consumo en streaming se hace un hueco en el mercado español}

Esta situación ya ha sido advertida en estudios como el de Gallego (2013, p. 13), quien señala que el usuario consume el contenido sin importarle la plataforma y por ello, además de elaborar contenidos de calidad, el negocio de la televisión debe crear su propia comunidad y generar conversación con la audiencia en torno a la marca.

Por último, el contenido más visto fueron los vídeos cortos (54\%), las series (46\%) y películas (32\%) (CNMC, 2017). El $72 \%$ de las series emitidas en España son de EUA (Barlovento Comunicación, 2017b). El $86 \%$ se ha emitido en cadenas de pago y el $56 \%$ en abierto. Además, Kantar Media (2017) señala que el $50 \%$ de la población con acceso a internet consume series en la Red. A ello contribuyen plataformas como Netflix y $H B O$, propietarias de los derechos de emisión de algunas de las series más vistas. El estudio de esta consultora manifiesta una marcada tendencia al cambio en la forma de consumo: un $30 \%$ de los consumidores declara utilizar la televisión a la carta para crear sus propios horarios de programas de televisión.

\subsection{Social media y engagement de la audiencia}

La necesidad de entablar una conversación mencionada por Gallego (2013, p. 13) se produce fundamentalmente en las redes sociales, donde se busca generar engagement o implicación con la audiencia. Los "me gusta", comentarios y comparticiones miden ese compromiso o fidelidad (Huertas; Setó-Pàmies; Míguez-González, 2015, p. 17).

El rápido desarrollo de los social media y su integración en la producción (Zenith, 2018), distribución y recepción de televisión ha obligado a profesionales y académicos a reconsiderar cómo entender, estimular y medir el compromiso de la audiencia (Moe; Poell; Van-Dijck, 2015, p. 100). En estas plataformas todo gira en torno a participar y compartir.

Compartir información es algo cotidiano (Berger; Milkman, 2012), lo que Dafonte-Gómez y Martínez-Rolán (2016, p. 509) identifican como "la era del share" (compartir). Entre las motivaciones para compartir se encuentra la necesidad de compartir información que se considera relevante, así como una forma de diferenciarse a través de las elecciones de consumo cultural (Dafonte-Gómez; Martínez-Rolán, 2016, p. 509). La utilidad de la información y los elementos inesperados o que sorprenden son los más atractivos para viralizar contenidos en Twitter (Al-Rawi, 2017, p. 14; Pirouz et al., 2015, p. 86). El humor suele ser otro de los principales elementos que favorece la viralidad (Wendelin; Engelmann; Neubarth, 2017, p. 137; Halpern; Quintas-Froufe; Fernández-Medina, 2016, p. 373).

En el hecho de compartir un contenido intervienen factores formales, como el incluir un vídeo o el tamaño del texto (AlRawi, 2017, p. 2; Wendelin; Engelmann; Neubarth, 2017, p. 150). La imagen funciona mejor que el texto, ya que es lo primero en lo que se fijan los usuarios (Maciá; Santonja, 2016, p. 58).

En ocasiones los contenidos de carácter meramente promocional pueden generar rechazo entre los usuarios. Las redes sociales son ante todo conversación. Para ello, se debe crear una comunidad de seguidores identificados con los valores de la empresa y las bondades del producto creando contenido propio. Sólo cuando esa comunidad crezca se pueden aumentar los mensajes promocionales (Maciá; Santonja, 2016, p. 23).

Frente a los contenidos promocionales, las noticias que se comparten junto a una pregunta que invita a los lectores a participar, logran un mayor consumo e implicación (Oeldorf-Hirsch; Sundar, 2015; Huertas; Setó-Pàmies; Míguez-González, 2015, p. 18).

Otro de los formatos que ha ganado terreno en términos de engagement es el meme, que ha generado un conjunto de reglas estilísticas en base a agregar texto a las imágenes: por ejemplo, agregar el mismo texto a varias imágenes, o agregar texto diferente a una imagen común. Al igual que los emoticonos, los memes son una representación de la cultura, normalmente una broma, que gana influencia a través de la transmisión online (Davison, 2012, p. 122).

Por otro lado, cuantos más comentarios leen los usuarios en redes sociales, mayor es el efecto que tienen en su conducta televisiva. Facebook y Twitter son las que más se utilizan 
para hablar de televisión (Halpern; Quintas-Froufe; Fernández-Medina, 2016, p. 373)

Por último, los usuarios tienden a pulsar la opción like más a menudo que comentar o compartir, como demuestran estudios realizados en diferentes sectores:

- canales de televisión temática: Fernández-Gómez; Díazdel-Campo, 2014;

- juguetes: Fernández-Gómez; Díaz-del-Campo, 2015;

- salud: Fernández-Gómez; Díaz-del-Campo, 2016.

Asimismo, un estudio sobre la estrategia de Netflix en España (Fernández-Gómez; Martín-Quevedo, 2018) reveló que los seguidores de Twitter prefieren esta opción frente al retweet o al comentario. Conocer qué hace que un contenido se comente o comparta resulta de utilidad en la gestión de la marca en medios sociales.

El usuario consume el contenido online sin importarle la plataforma

\section{Objetivos y método}

Esta investigación se centra en la comunicación de Netflix en Twitter. El objetivo es determinar qué características presentan los mensajes que generan un mayor engagement entre su audiencia. Netflix es la plataforma de pago que más ha crecido en el mercado español, y es ya un competidor de la televisión tradicional en este país.

Conocer lo que Netflix publica y utiliza exitosamente para involucrar a sus seguidores permite comprender lo que la audiencia social valora de una marca a la hora de entablar conversación. Esto permitirá a los demás operadores mejorar su estrategia en redes sociales.

Se ha seleccionado Twitter por ser la más empleada en actividades de segunda pantalla (Segado-Boj; Grandío; Fernández-Gómez, 2015, p. 228), así como para acceder y monitorizar a la audiencia (Wilson, 2015).

Se han planteado tres preguntas de investigación:

P1. ¿Cuáles son las características de los tweets que generan más conversación con los seguidores?

P2. ¿Cuáles son las características de los tweets que más comparten los seguidores?

P3. ¿Cuáles son las características de los tweets que más gustan a los seguidores?

En primer lugar se observa si los tweets con mejor engagement son originales o bien retweets, lo que demostraría una estrategia de creación propia en redes sociales, frente a una en la que simplemente se dedique a compartir contenidos publicados por otros.

Atendiendo a la bibliografía previa, como se ha expuesto en el apartado anterior, se consigue una mayor involucración de la audiencia mediante el uso de las llamadas a la participación y se rechazan los contenidos promocionales. Por ello se estudia qué tipo de objetivo persiguen los mensajes que generan más participación, gustan y se comparten.
Asimismo, las series de ficción se han convertido en el producto estrella de estas plataformas, por lo que se espera que las publicaciones que más engagement generen sean aquellas que hablan sobre estos contenidos (Garza, 2017).

Por último, ya que las imágenes son las que atraen una mayor atención del público, se prevé que los mensajes que obtienen mejores resultados en los tres indicadores señalados sean los que emplean este recurso. Por ello se analiza el tipo de recursos presentes en las publicaciones con mejor engagement.

La muestra estudiada corresponde al primer año de Netflix en Twitter (del 13 de diciembre de 2015 al 12 de diciembre de 2016). Los mensajes se han clasificado en las categorías de análisis mencionadas (tweet original o retweet, objetivo de la publicación, tipo de contenido -serie-, recursos del mensaje y número de comentarios, retweets y "me gusta") a través de una ficha de elaboración propia (Fernández-Gómez; Martín-Quevedo, 2018) y confeccionada a partir de estudios precedentes (Díaz-del-Campo; Segado-Boj, 2013; Segado-Boj; Grandío; Fernández-Gómez, 2015, p. 228; González-Molina; Ramos-del-Cano, 2014).

Durante el período analizado Netflix publicó un total de 1.048 tweets. De ellos, 914 obtuvieron comentarios; 928 fueron retweeteados y 1.017 obtuvieron "me gusta"2. Para conocer qué caracteriza a los mensajes que generaron más engagement se siguió la lógica del algoritmo Twitter Decahose, eligiendo una muestra representativa del $10 \%$ del total, tal y como han aplicado trabajos como el de Brantner y Rodríguez-Amat (2016).

Para cada uno de los contenidos analizados (los que generan más conversación, más se comparten y más gustan) la muestra final se configura como se indica en la tabla 1.

\section{Resultados}

\section{P1. Características de los tweets que generan más conversación con los seguidores}

En la muestra Decahose de los posts con comentarios -un total de 91 mensajes- el reparto de comentarios por tweet fue desigual. La publicación con menos comentarios obtuvo 23 respuestas y 500 la que más. Esto supone una media de 11 respuestas por tweet y una desviación estándar de 64,6 comentarios.

El 93,4\% de los tweets que más conversación generaron fueron de autoría propia de Netflix, lo que refuerza la necesidad de crear contenido mayoritariamente propio al ser lo que más se comenta.

Respecto al objetivo (tabla 2), la mayoría de los posts promocionan los contenidos $(63,7 \%)$, ofrecen información

Tabla 1. Muestra

\begin{tabular}{|l|c|c|}
\cline { 2 - 3 } \multicolumn{1}{c|}{} & Total & N (10\% Decahose) \\
\hline Tweets con comentarios & 914 & 91 \\
\hline Tweets compartidos & 928 & 93 \\
\hline Tweets con "me gusta" & 1.017 & 102 \\
\hline
\end{tabular}


(33\%) y, finalmente, promocionan la plataforma $(30,8 \%)$. Estos objetivos no son excluyentes. Se aprecia que los usuarios conectaron más fácilmente con contenidos específicos antes que con la marca Netflix.

Entre los recursos utilizados no aparece una mayoría clara. Lo más habitual son los hashtags (44\%). Esto está relacionado con que los mensajes que promocionan contenidos son los que generan más conversación, ya que estas etiquetas se emplean para clasificar los programas promocionados (\#Narcos, \#StrangerThings, etc.). Por otro lado, es un recurso versátil al poder utilizarse junto a otros y requiere menos trabajo que un vídeo o una imagen. En un segundo nivel de uso se encuentran los vídeos $(26,4 \%)$ y las fotos $(24,2 \%)$. La participación de los usuarios en este perfil no está vinculada especialmente a ninguno de los dos formatos. En un tercer nivel se sitúan los memes $(13,2 \%)$ y los emoticonos $(8,8 \%)$.

\section{Las redes sociales favorecen la conversa- ción con la marca}

Las series son los contenidos que más comentarios generaron. Esto puede deberse al compromiso necesario para ver una serie (varias entregas), en contraposición a una película (relato unitario). Las series pueden incrementar el engagement por el deseo de continuar hablando de ellas entre episodios y temporadas. Además, de las 9 series que fueron citadas entre los posts más comentados (tabla 3), 5 son de producción propia -incluidos los tres primeros puestos de la tabla-, lo que es un éxito de la política de producción de Netflix.

La serie más exitosa en número de comentarios (1.333) y en promedio de respuestas por tweet $(74,05)$ fue Narcos; también con mucha diferencia la que generó más posts con un alto engagement (18). En segundo lugar se situó Stranger things, con un número menor de comentarios (405), aunque con 6 publicaciones.

La tercera serie, Orange is the new black, merece una atención especial: Aunque es producida por Netflix, se emite también en Movistart, y Netflix no puede emitir la última temporada al estar reservado su estreno a la plataforma de Telefónica. Ello implica que la plataforma americana apostó por una estrategia de promoción diferente. Orange is the new black no aparece mencionada en el texto de ninguna de las publicaciones, sino que su promoción se basa en el uso de elementos visuales: una foto, un meme y un vídeo. Además, en dos de los tres casos la serie aparece mencionada junto a otros contenidos, y no por sí sola.

Por último, al observar los diez tweets más comentados (tabla 4), se encuentran algunas diferencias respecto al conjunto de la muestra. A pesar de que casi todos los mensajes fueron de Netflix, entre
Tabla 2. Características de los tweets

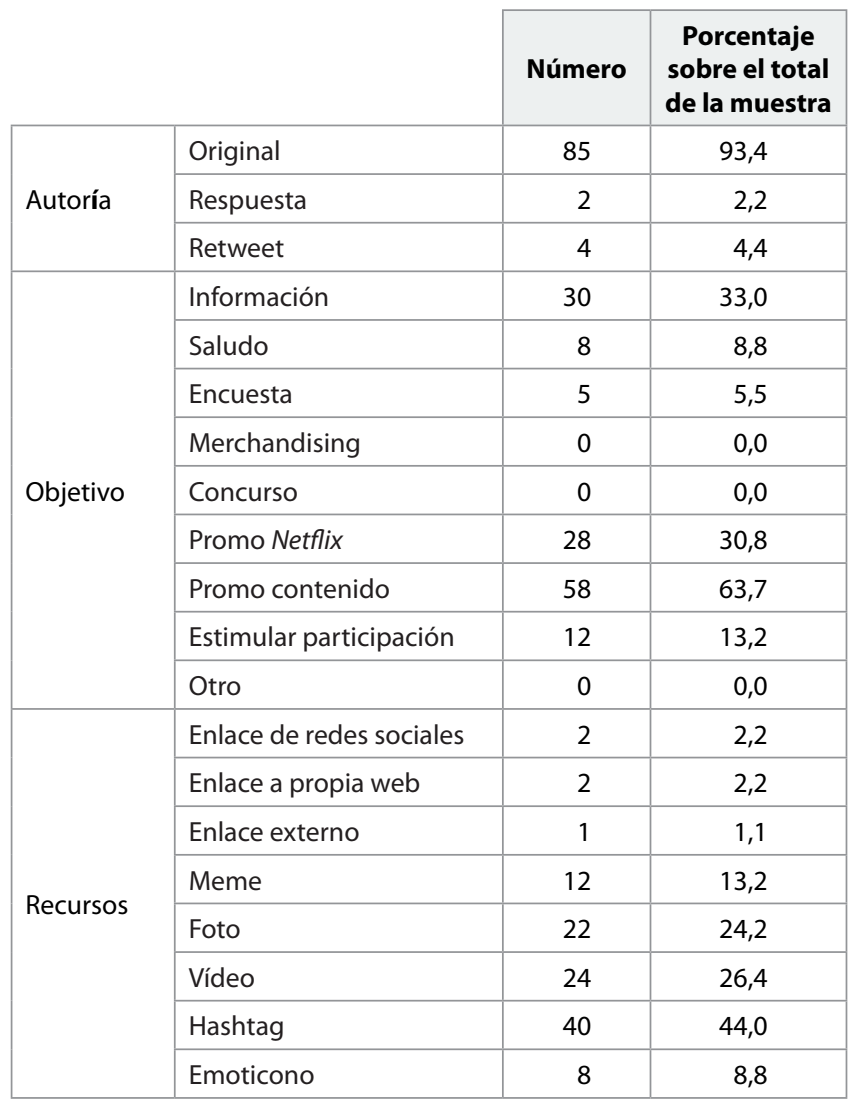

los diez primeros aparecen 3 retweets de cuentas con gran proyección:

- Bill Burr (@billburr), un cómico estadounidense con más de un millón de seguidores;

- Stephen King (@StephenKing), escritor con casi cinco millones de followers;

- Real Madrid (@realmadrid), con casi 30 millones.

Por lo tanto, el nivel de respuestas en estas publicaciones radica en el alcance y proyección de sus autores.

La mayoría de los posts se dedicaron a la promoción de los contenidos, exclusivamente o junto a otras cuestiones ( 7 de los 10 posts). La serie más comentada fue Narcos, donde Netflix empleó la estrategia de intentar buscar la participación de los usuarios a través de una pregunta. En la segunda

Tabla 3. Comentarios según contenido mencionado

\begin{tabular}{|l|c|c|c|c|c|}
\hline \multicolumn{1}{|c|}{ Contenido } & $\begin{array}{c}\text { Número de } \\
\text { tweets }\end{array}$ & $\begin{array}{c}\text { Respuestas } \\
\text { totales }\end{array}$ & $\begin{array}{c}\text { Respuestas } \\
\text { promedio }\end{array}$ & $\begin{array}{c}\text { Tipo de } \\
\text { contenido }\end{array}$ & Producción \\
\hline Narcos & 18 & 1.333 & 74,1 & Serie & Propia \\
\hline Stranger things & 6 & 405 & 67,5 & Serie & Propia \\
\hline Orange is the new black & 3 & 218 & 72,6 & Serie & Propia \\
\hline The walking dead & 3 & 127 & 42,3 & Serie & Ajena \\
\hline Friends & 2 & 94 & 47,0 & Serie & Ajena \\
\hline Big bang theory & 3 & 91 & 30,3 & Serie & Ajena \\
\hline Rick y Morty & 2 & 84 & 42,0 & Serie & Ajena \\
\hline Black mirror & 2 & 79 & 39,5 & Serie & Propia \\
\hline Daredevil & 3 & 75 & 25,0 & Serie & Propia \\
\hline
\end{tabular}


Tabla 4. Los diez mensajes con más comentarios

\begin{tabular}{|c|c|c|c|c|c|}
\hline Mensaje & $\begin{array}{l}\text { Número de } \\
\text { comentarios }\end{array}$ & Tipo & Objetivo & $\begin{array}{l}\text { Contenido } \\
\text { promocionado }\end{array}$ & Recursos \\
\hline $\begin{array}{l}\text { Season two of } F \text { is for family is finally } \\
\text { official!!!! Thank you for watching! More to } \\
\text { come! \#FisForFamily }\end{array}$ & 500 & Retweet & Promo contenido & $F$ is for family & Vídeo Hashtag \\
\hline $\begin{array}{l}\text { ¿Cuál es la forma correcta de escribir esto, } \\
\text { @RAEInforma? 1. Hijueputa 2. Hijoeputa } 3 . \\
\text { Güeputa }\end{array}$ & 255 & Original & $\begin{array}{l}\text { Promo contenido } \\
\text { Estimular participación }\end{array}$ & Narcos & Vídeo \\
\hline 4815162342 & 223 & Original & Promo contenido & Perdidos & \\
\hline $\begin{array}{l}\text { My only question about the Netflix series } \\
\text { STRANGER THINGS is whether or not it will } \\
\text { be popular enough to crash their servers. It } \\
\text { might be. }\end{array}$ & 211 & Retweet & Promo contenido & Stranger things & \\
\hline $\begin{array}{l}\text { ¿Qué series estás viendo mientras esperas la } \\
\text { segunda temporada de \#Narcos? }\end{array}$ & 172 & Original & $\begin{array}{l}\text { Promo contenido } \\
\text { Estimular participación }\end{array}$ & Narcos & Hashtag \\
\hline $\begin{array}{l}\text { Lo pediste y por fin te traemos una nueva } \\
\text { forma de vernos }\end{array}$ & 153 & Original & $\begin{array}{l}\text { Información } \\
\text { Promo Netflix }\end{array}$ & $\begin{array}{l}\text { The crown } \\
\text { House of cards } \\
\text { Una escalera al cielo } \\
\text { Stranger things } \\
\text { Narcos } \\
\text { Orange is the new black } \\
\text { Black mirror }\end{array}$ & Vídeo \\
\hline Lo de hoy es: amor a primer streaming & 151 & Original & Promo contenido & Narcos & Vídeo \\
\hline "Mi primer maratón fue..." & 135 & Original & $\begin{array}{l}\text { Promo Netflix } \\
\text { Estimular participación }\end{array}$ & & \\
\hline $\begin{array}{l}\text { Has escuchado bien \#DoctorWho aterriza el } \\
31 \text { de marzo en España }\end{array}$ & 132 & Original & $\begin{array}{l}\text { Promo contenido } \\
\text { Información }\end{array}$ & Doctor Who & $\begin{array}{l}\text { Hashtag } \\
\text { Meme }\end{array}$ \\
\hline 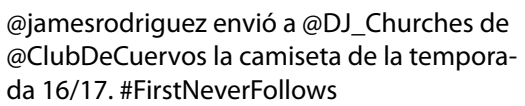 & 116 & Retweet & Información & ClubDeCuervos & Emoticono \\
\hline
\end{tabular}

publicación lanzó una duda lingüística a la Real Academia Española sobre uno de los términos más usados durante la serie y en el quinto tweet preguntó a los usuarios qué otras series consumen hasta que se estrene la siguiente temporada.

También es reseñable el caso del post "Lo pediste y por fin..." en el que anunciaron la posibilidad de descargar algunos contenidos para verlos en diferido. Ello provocó muchos comentarios, primero de dudas, y después con muestras de alegría por parte de los usuarios. El vídeo con el que se anunció este nuevo servicio apenas daba detalles sobre cómo funcionaría, sino que se dedicaba a repasar las series más destacadas del catálogo de la plataforma.

Uno de los productos audiovisuales de consumo favorito en la Red son las series de televisión

Finalmente, en otro de los casos ("Lo de hoy es...") la plataforma recurrió al storytelling: un vídeo que no cuenta nada sobre la serie, sino un anuncio musical sobre cómo un chico descubre la serie favorita de una chica y la ve entera para iniciar una conversación con ella. Aunque es el único caso en el año analizado, demuestra la capacidad de Netflix de diversificar los enfoques para conseguir sus propósitos.

\section{P2. Características de los tweets que más comparten los seguidores}

La muestra Decahose de los mensajes con retweets está formada por 93 publicaciones (tabla 1), que presentan una media de 860 comparticiones por post. Estos retweets se movieron en un rango que osciló entre 353 y 4.200 y una desviación estándar de 722,1. Se entiende por retweets el número de veces que ese mensaje ha sido retweeteado por distintos usuarios desde su fecha de post hasta el día del análisis. Esta diferencia entre retweets mínimos y máximos se debe en buena medida a los tres mensajes procedentes de cuentas con muchos más seguidores a los que Netflix hizo retweet: las de Bill Burr, Stephen King y el Real Madrid.

También en este caso la mayoría fueron mensajes originales (tabla 5), un 90,3\%. En la misma línea, el objetivo que prevaleció fue el de promocionar contenido (72\%), reforzando la idea de que los usuarios aprecian especialmente los mensajes referidos al catálogo más que a la plataforma. En un segundo nivel, en un $25,8 \%$, aparecen informar y promocionar Netflix. En tercer lugar destaca el saludo (14\%).

Los hashtags fueron también los recursos más utilizados, en un $49,5 \%$ de los casos. Sin embargo aquí aparecen algunas diferencias respecto al primer indicador de engagement: los vídeos $(32,3 \%)$ fueron más populares que las fotos $(17,2 \%)$ así como los memes (24,7\%). De esta forma se invierten las 
cifras respecto a los comentarios: el $24,2 \%$ de los posts más comentados incluían una foto, mientras que sólo el 13,2\% tenían un meme (tabla 2); por el contrario, el $24,7 \%$ de los que reciben retweets llevan memes y sólo el $17,2 \%$ incluye una foto (tabla 5).

De nuevo las series son los contenidos que reciben más retweets (tabla 6). En 6 de los 8 casos son también de producción propia. Una vez más, Narcos y Stranger things lideran el ranking, aunque la segunda mejora sus cifras.

\section{Conocer cómo Netflix genera engage-} ment con sus seguidores permite comprender lo que la audiencia social valora de una marca a la hora de entablar conversación

Dos series obtuvieron un promedio de retweets superior a Narcos:

1) Orange is the new black, con la media más alta de retweets por mensaje: 1.056. Es un caso particular, porque todos sus posts fueron junto a otros contenidos, y formaron parte de campañas más amplias, por lo que parte de su popularidad se explica por ir asociada a otros productos de éxito. El primer post, compartido con Jessica Jones, fue su inclusión en la campaña de apoyo al Orgullo LGTB. El segundo post fue el ya mencionado en el que se anunció la nueva posibilidad de descargar los contenidos y verlos sin conexión, para lo cual Netflix produjo un vídeo con algunos de sus contenidos, pero sin destacar ninguno en particular. Finalmente, en el tercero de estos posts, la plataforma buscaba promocionarse a sí misma mediante "Los diez mandamientos de Netflix". Actores de varias de sus producciones, incluyendo Orange is the new black, recitaban las normas de este "código de buena conducta". De esta forma, no parece que Orange is the new black, a pesar de las cifras, haya generado demasiado engagement por parte de los usuarios al no promocionarse en solitario.

2) El otro caso destacable es Jessica Jones, una serie que en sólo dos posts lograron la media de retweets más alta. Uno era un vídeo con una secuencia de la serie, vinculándola al reto viral mannequin challenge, pero el otro post que acumulaba más retweets era el mencionado vídeo de apoyo al movimiento Orgullo LGTB que empleaba escenas de varios contenidos de Netflix en las que aparecían personajes homosexuales mostrando su amor.

En los posts que más retweets recibieron (tabla 7), siguen figurando los tres de cuentas externas. Se repiten algunos de los mensajes más comentados, como la pregunta a la $R A E$, el anuncio musical y la incorporación de Perdidos. En este último caso la estrategia
Tabla 5. Características de los tweets

\begin{tabular}{|c|c|c|c|}
\hline & & Número & $\begin{array}{c}\text { Porcentaje } \\
\text { sobre el } \\
\text { total de la } \\
\text { muestra }\end{array}$ \\
\hline \multirow{3}{*}{ Autoría } & Originales & 84 & 90,3 \\
\hline & Respuestas & 2 & 2,2 \\
\hline & Retweets & 7 & 7,5 \\
\hline \multirow{9}{*}{ Objetivo } & Información & 24 & 25,8 \\
\hline & Saludo & 13 & 14,0 \\
\hline & Encuesta & 0 & 0,0 \\
\hline & Merchandising & 1 & 1,1 \\
\hline & Concurso & 0 & 0,0 \\
\hline & Promo Netflix & 24 & 25,8 \\
\hline & Promo contenido & 67 & 72,0 \\
\hline & Estimular participación & 1 & 1,1 \\
\hline & Otro & 0 & 0,0 \\
\hline \multirow{8}{*}{ Recursos } & Enlace a redes sociales & 1 & 1,1 \\
\hline & Enlace a la propia web & 1 & 1,1 \\
\hline & Enlace externo & 1 & 1,1 \\
\hline & Memes & 23 & 24,7 \\
\hline & Foto & 16 & 17,2 \\
\hline & Vídeo & 30 & 32,3 \\
\hline & Hashtag & 46 & 49,5 \\
\hline & Emoticono & 9 & 9,7 \\
\hline
\end{tabular}

era deliberadamente críptica, pues el post sólo contenía una secuencia de números, sin más explicaciones. Netflix buscaba realizar un guiño al fenómeno fan que generó la serie originalmente, y que reconocería el código, que era un elemento recurrente de la trama. La misma estrategia se empleó en otro post sobre Stranger things en el que se limitaban a enunciar el nombre de sus protagonistas ("Mike Lucas Dustin...").

Otra estrategia de Netflix es el uso inteligente de emoticonos para crear imágenes llamativas en su línea de producción de contenido propio. Ocurre en el noveno tweet más compartido: "Está en tu ADN" (imagen 1). Esto muestra la versatilidad de la estrategia que Netflix utiliza para promocionar su plataforma en clave de humor.

Tabla 6. Retweets según contenido mencionado

\begin{tabular}{|l|c|c|c|c|c|}
\hline \multicolumn{1}{|c|}{ Contenido } & $\begin{array}{c}\text { Número de } \\
\text { tweets }\end{array}$ & $\begin{array}{c}\text { Retweets } \\
\text { totales }\end{array}$ & $\begin{array}{c}\text { Retweets } \\
\text { promedio }\end{array}$ & $\begin{array}{c}\text { Tipo de } \\
\text { contenido }\end{array}$ & Producción \\
\hline Narcos & 25 & 23.025 & 921,0 & Serie & Propia \\
\hline Stanger things & 15 & 10.617 & 707,8 & Serie & Propia \\
\hline Orange is the new black & 3 & 3.168 & $1.056,0$ & Serie & Propia \\
\hline Black mirror & 5 & 2.881 & 576,2 & Serie & Propia \\
\hline Jessica Jones & 2 & 2.705 & $1.352,5$ & Serie & Propia \\
\hline Friends & 2 & 1.175 & 587,0 & Serie & Ajena \\
\hline $\begin{array}{l}\text { Una serie de catastróficas } \\
\text { desdichas }\end{array}$ & 2 & 1.012 & 506,0 & Serie & Propia \\
\hline Breaking bad & 2 & 877 & 438,5 & Serie & Ajena \\
\hline
\end{tabular}


Tabla 7. Los diez mensajes con más retweets

\begin{tabular}{|c|c|c|c|c|c|}
\hline Mensaje & $\begin{array}{l}\text { Número de } \\
\text { retweets }\end{array}$ & Tipo & Objetivo & $\begin{array}{l}\text { Contenido } \\
\text { promocionado }\end{array}$ & Recursos \\
\hline $\begin{array}{l}\text { @jamesrodriguez envió a @DJ_Churches de @ } \\
\text { ClubDeCuervos la camiseta de la temporada } \\
\text { 16/17. \#FirstNeverFollows }\end{array}$ & 4.200 & Retweet & Información & ClubDeCuervos & Emoticono \\
\hline $\begin{array}{l}\text { ¿Cuál es la forma correcta de escribir esto, } \\
\text { @RAEInforma? 1. Hijueputa 2. Hijoeputa } 3 . \\
\text { Güeputa }\end{array}$ & 3.536 & Original & $\begin{array}{l}\text { Promocontenido } \\
\text { Estimular participación }\end{array}$ & Narcos & Vídeo \\
\hline $\begin{array}{l}\text { Season two of } \mathrm{F} \text { is for family is finally official!!!! } \\
\text { Thank you for watching! More to come! } \\
\text { \#FisForFamily }\end{array}$ & 3.472 & Retweet & Promo contenido & Fis for family & Vídeo Hashtag \\
\hline 4815162342 & 2.428 & Original & Promo contenido & Perdidos & \\
\hline Lo de hoy es: amor a primer streaming & 2.320 & Original & Promo contenido & Narcos & Vídeo \\
\hline $\begin{array}{l}\text { La timidez es eso que dura hasta que alguien } \\
\text { menciona tu serie favorita }\end{array}$ & 2.312 & Original & Promo Netflix & & \\
\hline $\begin{array}{l}\text { Las referencias a los ` } 80 \text { que no viste en } \\
\text { \#StrangerThings }\end{array}$ & 2.052 & Original & Promo contenido & Stranger things & Vídeo Hashtag \\
\hline Para gustos, colores. \#OrgulloLGTB & 1.955 & Original & $\begin{array}{l}\text { Saludo } \\
\text { Promo Netflix } \\
\text { Promo contenido }\end{array}$ & $\begin{array}{l}\text { Sense } 8 \\
\text { Grace and Frankie } \\
\text { Orange is the new black } \\
\text { London spy } \\
\text { Jessica Jones } \\
\text { Unbreakable Kimmy Schmidt }\end{array}$ & Vídeo Hashtag \\
\hline Está en tu ADN. & 1.945 & Original & Promo Netflix & & Foto \\
\hline $\begin{array}{l}\text { My only question about the Netflix series } \\
\text { STRANGER THINGS is whether or not it will } \\
\text { be popular enough to crash their servers. It } \\
\text { might be. }\end{array}$ & 1.900 & Retweet & Promo contenido & Stranger Things & \\
\hline
\end{tabular}

Netflix España @NetflixES

Está en tu ADN.

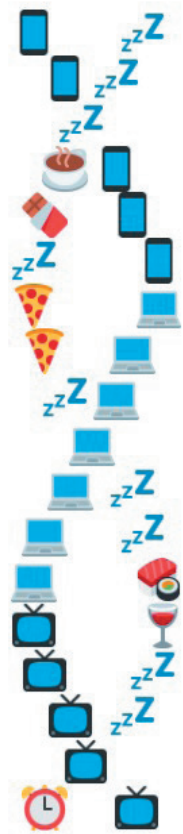

5:38 - 21 feb. 2016

\subsection{Retweets 1.898 Me gusta 6900000 \\ Q $22 \quad$ T] $1.8 \mathrm{~K} \quad$ O $1.9 \mathrm{~K}$}

\section{P3. Características de los tweets que más gustan a los seguidores}

La muestra de mensajes populares está compuesta por 102 tweets (tabla 1), que obtuvieron una media de 1.075,8 "me gusta", con un rango entre 429 y 8.302. Los "me gusta" son el número de usuarios que han pulsado el botón "me gusta" en el tweet desde su publicación hasta el día del análisis. El reparto fue desigual, con una desviación estándar de $1.320,7$, mayor que la propia media. En buena medida, esto se debe a los tres mensajes de cuentas más populares ya mencionados, pues cada uno de ellos tiene una media de 7.534 "me gusta". Excluyendo estos mensajes, la media desciende a 880 por tweet.

\section{Los tweets que más conversación ge- neran son los de creación propia, que promocionan contenido específico, cla- sifican con un hashtag y acompañan de una imagen o vídeo}

Como en los casos anteriores, la mayoría de los mensajes fueron originales (tabla 8), un 91,2\%. Se repitieron también los objetivos de los mensajes, aunque la diferencia fue más marcada: el 70,6\% estaban dedicados a promocionar el contenido frente a los que ofrecían información $(29,4 \%)$, los que promocionaban la plataforma $(25,5 \%)$, y los saludos $(9,8 \%)$.

El recurso más utilizado fue de nuevo el hashtag (54,9\%). Sin embargo, sí que existe una diferencia más marcada en- 
tre los posts con vídeos (33,3\%) y los que emplean imágenes $(21,6 \%)$ o memes $(21,6 \%)$. A diferencia de los más comentados y al igual que los más compartidos, sí que parece que el hecho de elegir un vídeo genera más "me gusta" que el uso de otros recursos.

En todos los casos las series son las que más gustan (tabla 9), de las cuales sólo una no es de producción propia, Friends. También en los likes se repite el éxito de Narcos y Stranger things, que se consolidan como las más populares de la plataforma.

\section{Netflix utiliza una gran variedad de estra- tegias de engagement, como identificar- se con causas sociales, el storytelling o el uso creativo de emoticonos o hashtags}

Por otro lado, aunque Narcos consiguió generar engagement tanto en comentarios como en "me gusta", con Stranger things los usuarios mostraron interés, pero parecieron más inclinados a limitar éste a un engagement de menor intensidad, al no requerir más que pulsar un botón.

Es significativo el caso ya mencionado en el punto anterior de Jessica Jones, una serie con pocos likes en total y la que más en promedio. Dado que en este caso sí hay una publicación dedicada en exclusiva a esta serie, y con numerosos "me gusta" y retweets, sí parece que ha logrado el favor de los seguidores. La estrategia de aprovechar eventos sociales para promocionar sus contenidos fue usada exitosamente una vez más.

Respecto a los posts que más gustaron (tabla 10), como en otros casos los tres primeros puestos estuvieron copados por los retweets de cuentas externas. El resto de los contenidos son originales.

Reaparecen el Orgullo LGTB, el vídeo de localización de Stranger things, la campaña musical, el mensaje a la $R A E$ sobre Narcos y el anuncio de la incorporación al catálogo de Perdidos.

En este ranking también aparecen otros ejemplos de estrategias utilizadas por Netflix. Una es la de la localización, especialmente en tono de comedia, como hicieron con el post dedicado a Stranger things ("Las referencias a los 80..."). Aprovechando la nostalgia de los años ochenta, la plataforma creó un vídeo en el que incluía elementos de la cultura española en la serie: personajes que reproducen diálogos del dúo cómico Martes y 13, televisiones en las que aparece el Un, dos, tres..., monstruos sustituidos por Espinete de Barrio Sésamo, etc. La intención cómica queda reforzada cuando al final del vídeo aparece la carátula de la serie, subtitulada como "cosicas raras".
Tabla 8. Características de los tweets

\begin{tabular}{|c|c|c|c|}
\hline & & & \\
\hline & & \multirow{2}{*}{$\begin{array}{c}\text { Número } \\
93\end{array}$} & \multirow{2}{*}{$\begin{array}{c}\begin{array}{c}\text { Porcentaje } \\
\text { sobre el total } \\
\text { de la muestra }\end{array} \\
91,2\end{array}$} \\
\hline \multirow{3}{*}{ Autoría } & Originales & & \\
\hline & Respuesta & 1 & 1,0 \\
\hline & Retweet & 8 & 7,8 \\
\hline \multirow{9}{*}{ Objetivo } & Información & 30 & 29,4 \\
\hline & Saludo & 10 & 9,8 \\
\hline & Encuesta & 0 & 0,0 \\
\hline & Merchandising & 1 & 1,0 \\
\hline & Concurso & 0 & 0,0 \\
\hline & Promo Netflix & 26 & 25,5 \\
\hline & Promo contenido & 72 & 70,6 \\
\hline & Estimular participación & 1 & 1,0 \\
\hline & Otro & 0 & 0,0 \\
\hline \multirow{8}{*}{ Recursos } & Enlace a redes sociales & 1 & 1,0 \\
\hline & Enlace a la propia web & 1 & 1,0 \\
\hline & Enlace externo & 1 & 1,0 \\
\hline & Memes & 22 & 21,6 \\
\hline & Foto & 22 & 21,6 \\
\hline & Vídeo & 34 & 33,3 \\
\hline & Hashtag & 56 & 54,9 \\
\hline & Emoticono & 12 & 11,8 \\
\hline
\end{tabular}

Otra de las estrategias empleadas fue la de identificarse con una causa social, como hicieron con la mencionada campaña a favor del Orgullo LGTB. Más allá del mensaje reivindicativo, Netflix solamente empleó imágenes de series de producción propia, lo que sugiere una clara consciencia de intentar enmarcar el aprovechar un evento ajeno en una estrategia consolidada, la de privilegiar sus propios contenidos.

\section{Conclusiones y discusión}

En primer lugar se concluye que los contenidos que mejor engagement consiguen en los tres parámetros estudiados (comentarios, comparticiones y likes) son los creados específicamente por la plataforma. En concreto, el 93,4\% de las publicaciones más comentadas, el $90,4 \%$ de los más retweeteados y el $91,2 \%$ de los que más gustan. Esto encaja
Tabla 9. "Me gusta” según contenido mencionado

\begin{tabular}{|l|c|c|c|l|l|}
\hline \multicolumn{1}{|c|}{ Contenido } & $\begin{array}{c}\text { Número } \\
\text { de tweets }\end{array}$ & $\begin{array}{c}\text { “me gus- } \\
\text { ta" totales }\end{array}$ & $\begin{array}{c}\text { “me } \\
\text { gusta" } \\
\text { promedio }\end{array}$ & $\begin{array}{c}\text { Tipo de } \\
\text { contenido }\end{array}$ & $\begin{array}{c}\text { Produc- } \\
\text { ción }\end{array}$ \\
\hline Narcos & 21 & 25.012 & $1.191,9$ & Serie & Propia \\
\hline Stanger things & 15 & 13.272 & 884,8 & Serie & Propia \\
\hline Black mirror & 5 & 3.209 & 701,8 & Serie & Propia \\
\hline Jessica Jones & 2 & 2.926 & $1.463,0$ & Serie & Propia \\
\hline The crown & 2 & 1.592 & 796,0 & Serie & Propia \\
\hline Una serie de catastróficas desdichas & 3 & 1.441 & 480,3 & Serie & Propia \\
\hline Friends & 2 & 1.242 & 621,0 & Serie & Ajena \\
\hline Luke Cage & 2 & 1.021 & 510,5 & Serie & Propia \\
\hline
\end{tabular}


Tabla 10. Los diez mensajes con más "me gusta"

\begin{tabular}{|c|c|c|c|c|c|}
\hline Mensaje & $\begin{array}{l}\text { Número de } \\
\text { "me gusta" }\end{array}$ & Tipo & Objetivo & $\begin{array}{l}\text { Contenido } \\
\text { promocionado }\end{array}$ & Recursos \\
\hline $\begin{array}{l}\text { Season two of } \mathrm{F} \text { is for family is finally official!!!! } \\
\text { Thank you for watching! More to come! \#FisFor- } \\
\text { Family }\end{array}$ & 8.302 & Retweet & Promo contenido & F is for family & Vídeo Hashtag \\
\hline $\begin{array}{l}\text { My only question about the Netflix series STRANG- } \\
\text { ER THINGS is whether or not it will be popular } \\
\text { enough to crash their servers. It might be }\end{array}$ & 7.400 & Retweet & Promo contenido & Stranger things & \\
\hline $\begin{array}{l}\text { @jamesrodriguez envió a @DJ_Churches de @ } \\
\text { ClubDeCuervos la camiseta de la temporada } \\
\text { 16/17. \#FirstNeverFollows }\end{array}$ & 6.900 & Retweet & Información & ClubDeCuervos & Emoticono \\
\hline Lo de hoy es: amor a primer streaming & 5.160 & Original & Promo contenido & Narcos & Vídeo \\
\hline Mike Lucas Dustin Eleven $\| ! \wedge \wedge$ & 3.073 & Original & Promo contenido & Stranger things & \\
\hline $\begin{array}{l}\text { ¿Cuál es la forma correcta de escribir esto, @ } \\
\text { RAElnforma? 1. Hijueputa 2. Hijoeputa 3. Güeputa }\end{array}$ & 2.787 & Original & $\begin{array}{l}\text { Promo contenido } \\
\text { Estimular participación }\end{array}$ & Narcos & Vídeo \\
\hline 4815162342 & 2.559 & Original & Promo contenido & Perdidos & \\
\hline $\begin{array}{l}\text { Las referencias a los } 80 \text { que no viste en \#Stranger- } \\
\text { Things }\end{array}$ & 2.316 & Original & Promo contenido & Stranger things & Vídeo Hashtag \\
\hline $\begin{array}{l}\text { La timidez es eso que dura hasta que alguien } \\
\text { menciona tu serie favorita }\end{array}$ & 2.140 & Original & Promo Netflix & & \\
\hline Para gustos, colores. \#OrgulloLGTB & 2.114 & Original & $\begin{array}{l}\text { Saludo } \\
\text { Promo Netflix } \\
\text { Promo contenido }\end{array}$ & $\begin{array}{l}\text { Sense } 8 \\
\text { Grace and Frankie } \\
\text { OITNB } \\
\text { London Spy } \\
\text { Jessica Jones } \\
\text { Unbreakable Kimmy } \\
\text { Schmidt }\end{array}$ & Vídeo Hashtag \\
\hline
\end{tabular}

con la idea señalada por Maciá y Santonja (2016) sobre la necesidad de contar con una estrategia de creación de contenidos para que los usuarios se sientan identificados con los valores de la marca.

Por otro lado, como operador mundial ha recurrido también a retweets de cuentas con más popularidad, como las de Bill Burr, Stephen King y el Real Madrid. En ocasiones los mensajes originales estaban relacionados con sus servicios, pero en otras ha primado un criterio más oportunista, como en el caso del retweet al Real Madrid.

En segundo lugar, aunque sólo cuando esa comunidad crezca se pueden aumentar los mensajes promocionales, Netflix contaba ya en su primer año en España con seguidores que participan y aprecian las publicaciones promocionales sobre el catálogo de la plataforma en Twitter. Los mensajes promocionales han supuesto el $63,7 \%$ de las publicaciones más comentadas, el $72 \%$ de las más retweeteadas y el 70,6\% de las que más gustan. Tras los mensajes promocionales, los informativos son los que mejor acogida han tenido (33\%, $25,8 \%$ y $29,4 \%$ en cada medida de engagement). Dos objetivos que corroboran lo señalado por Dafonte-Gómez y Martínez-Rolán (2016, p. 509) sobre cómo para los usuarios el compartir información que consideren relevante para sus semejantes supone una forma de diferenciarse a través de las elecciones de consumo que realizan.

Es significativa la capacidad de Netflix para aprovechar eventos sociales o de actualidad para promocionar sus propios contenidos, e incluso memes populares del momento. Esto supone un esfuerzo por establecer un código común con su audiencia, por generar comunidad.
En tercer lugar, los recursos que contienen los mensajes son uno de los indicadores que mejor permite diferenciar por qué los usuarios los comentan, comparten o le dan a "me gusta". Tras el uso de la etiqueta propia de esta red social, el vídeo es el que mejor engagement consigue en los tres casos $(26,4 \%, 32,3 \%$ y $33,3 \%)$, pero el meme como nuevo formato es el que más se comparte y la imagen la que más comentarios suscita.

En cuarto lugar, el fenómeno seriéfilo señalado en la introducción de este trabajo queda confirmado en el análisis de involucración de los seguidores de Netflix. Las series y en especial las propias de la plataforma son las que mejores datos de engagement consiguen. Si bien no se ha analizado el $100 \%$ de los mensajes, todo apunta a un cambio en el modelo de consumo ya referido, en el que al público le interesa más el "qué" consume (en este caso, los contenidos más populares, series), que el "cómo" o la marca en que éstas se emiten.

Un análisis exploratorio de tipo cualitativo de los diez mensajes que mejor engagement obtienen en los tres indicadores apunta a que los recursos mencionados por estudios precedentes como las preguntas, el humor o el factor sorpresa incrementan la participación, lo que plantea nuevas investigaciones.

\section{Notas}

1. En la medición de audiencias se establece el mínimo de 4 años para considerar al espectador como "consciente". No quiere decir que el niño personalmente esté abonado, sino que consume televisión de pago (por ejemplo, que los padres le ponen Peppa Pig en Netflix). 
2. Debe tenerse en cuenta que a un mismo mensaje puede aplicarse dos o tres variables de engagement y por eso la suma de los tres parámetros no es igual al total de la muestra recogida.

\section{Agradecimientos}

Este trabajo ha sido parcialmente financiado por el proyecto Newsharing. Consumo de noticias en medios sociales. Análisis de factores en la selección y difusión de contenidos mediáticos, ref. CSO2017-86312-R (Mineco/AEI/Feder, UE).

\section{Referencias}

Al-Rawi, Ahmed (2017). "Viral news on social media". Digital journalism.

https://doi.org/10.1080/21670811.2017.1387062

Barlovento Comunicación (2017a). Análisis televisivo año 2016.

https://www.barloventocomunicacion.es

Barlovento Comunicación (2017b). Informe Barlovento: las series de EEUU en TV.

https://www.barloventocomunicacion.es/informes-barlovento/ series-de-eeuu-en-tv

Barlovento Comunicación (2017c). Informe Barlovento: TV pago y temáticas pago.

https://goo.gl/mVo7qH

Berger, Jonah; Milkman, Katherine L. (2012). "What makes online content viral?". Journal of marketing research, v. 49, n. 2, pp. 192-205.

https://doi.org/10.1509/jmr.10.0353

Brantner, Cornelia; Rodríguez-Amat, Joan-Ramon (2016). "New "Danger zone" in Europe: Representations of place in social media -supported protests". International journal of communication, v. 10, n. 22. pp. 299-320.

http://ijoc.org/index.php/ijoc/article/view/3788

Dafonte-Gómez, Alberto; Martínez-Rolán, Xabier (2016). "Del view al share: el papel de la comunicación viral en la transformación del ecosistema mediático". Palabra clave, v. 19 , n. 2, pp. 501-525.

https://doi.org/10.5294/pacla.2016.19.2.7

Davison, Patrick (2012). "The language of internet memes". En: Mandiberg, Michael (ed.). The social media reader. New York: NYU Press. ISBN: 9780814764060

https://goo.gl/DwdrWm

Díaz-del-Campo, Jesús; Segado-Boj, Francisco-José (2013). "La radio en Facebook. Análisis de los perfiles de las principales emisoras y programas radiofónicos en España". Icono 14, v. 11, n. 2, pp. 209-228.

https://doi.org/10.7195/ri14.v11i2.517

Fernández-Gómez, Erika; Díaz-del-Campo, Jesús (2014). "Los canales temáticos infantiles y juveniles en Facebook: Análisis de los perfiles de Disney Channel, Boing y Neox". Comunicación y hombre, n. 10, pp. 179.194.

https://dialnet.unirioja.es/servlet/articulo?codigo $=5344624$

Fernández-Gómez, Erika; Díaz-del-Campo, Jesús (2015). "La estrategia de marketing del sector del juguete en Face- book: análisis de la campaña de Navidad 2014 en España". Prisma social, n. 14 (junio-noviembre), pp. 124-151.

https://dialnet.unirioja.es/servlet/articulo?codigo $=5435325$

Fernández-Gómez, Erika; Díaz-del-Campo, Jesús (2016). "Comunicación sobre el cáncer en Facebook. Las asociaciones de Argentina, Chile, Colombia y España". Cuadernos. info, n. 38.

https://doi.org/10.7764/cdi.38.926

Fernández-Gómez, Erika; Martín-Quevedo, Juan (2018). "Connecting with audiences in new markets: Netflix's Twitter strategy in Spain". Journal of media business studies, v. 15, n. 1 , pp. $127-146$.

https://doi.org/10.1080/16522354.2018.1481711

Gallego, Francisco (2013). "Social TV analytics: nuevas métricas para una nueva forma de ver televisión". Index.comunicación, v. 3, n. 1, pp. 13-39.

http://journals.sfu.ca/indexcomunicacion/index.php/ indexcomunicacion/article/view/49

Garza, Virginia (2017). "La mitad de los internautas españoles ve series de televisión online". Kantar España insights, 17 julio.

https://es.kantar.com/media/tv/2017/julio-2017-datossobre-consumo-de-series-ante-el-estreno-de-juego-de-tronos

González-Molina, Sonia; Ramos-del-Cano, Fátima (2014). "Las redes sociales en el ámbito periodístico: ¿cómo usan los medios europeos de referencia sus perfiles en Twitter y Facebook?". Comunicación y hombre, v. 10, pp. 37-52.

https://dialnet.unirioja.es/servlet/articulo?codigo $=5344560$

Halpern, Daniel; Quintas-Froufe; Natalia; Fernández-Medina, Francisco (2016). "Interacciones entre la televisión y su audiencia social: hacia una conceptualización comunicacional". El profesional de la información, v. 25, n. 3, pp.367-375. https://doi.org/10.3145/epi.2016.may.06

Huertas, Assumpció; Setó-Pàmies, Dolors; Míguez-González, María-Isabel (2015). "Comunicación de destinos turísticos a través de los medios sociales". El profesional de la información, v. 24, n. 1, pp. 15-21.

https://doi.org/10.3145/epi.2015.ene.02

Maciá, Fernando; Santonja, María (2015). Marketing en redes sociales. Madrid: Ediciones Anaya Multimedia. ISBN: 9788441537262

Moe, Hallvard; Poell, Thomas; Van-Dijck, José (2015). "Rearticulating audience engagement. Social media and television". Television \& new media, v. 17, n. 2, pp. 99-107. https://doi.org/10.1177/1527476415616194

Oeldorf-Hirsch, Anne; Sundar, S. Shyam (2015). “Posting, commenting, and tagging: Effects of sharing news stories on Facebook". Computers in human behavior, v. 44, pp. 240-249. https://doi.org/10.1016/j.chb.2014.11.024

Pirouz, Dante M.; Johnson, Allison R.; Thomson, Mathew; Pirouz, Raymond (2015). "Creating online videos that engage viewers". MIT Sloan management review, v. 56, n. 4, pp. 83-88.

https://sloanreview.mit.edu/article/creating-online-videosthat-engage-viewers 
Samaniego, Rubén (2017). "Panel de hogares CNMC: El vídeo en streaming coge el vuelo, 1 de cada 4 hogares con internet ya lo utilizan". CNMC blog. Competencia, telecos, audiovisual, energía, transportes y +. 17 noviembre.

https://goo.gl/uEukPp

Segado-Boj, Francisco; Grandío, María-del-Mar; Fernández-Gómez, Erika (2015). "Social media and television: A bibliographic review on the Web of Science". El profesional de la información, v. 24, n. 3, pp. 227-234. https://doi.org/10.3145/epi.2015.may.02

Wendelin, Manuel; Engelmann, Ines; Neubart, Julia (2017).
"User rankings and journalistic news selection comparing news values and topics". Journalism studies, v. 18, n. 2, pp. 135-153. https://doi.org/10.1080/1461670X.2015.1040892

Wilson, Sherryl (2016). "In the living room: Second screens and TV audiences". Television \& new media, v. 17, n. 2, pp. 174-191.

https://doi.org/10.1177/1527476415593348

Zenith (2018). Online video forecasts 2018. Zenith. The ROI agency.

https://www.zenithmedia.com/product/online-videoforecasts-2018

\section{Colección de libros de bolsillo El profesional de la información (Editorial UOC)} Últimos títulos publicados
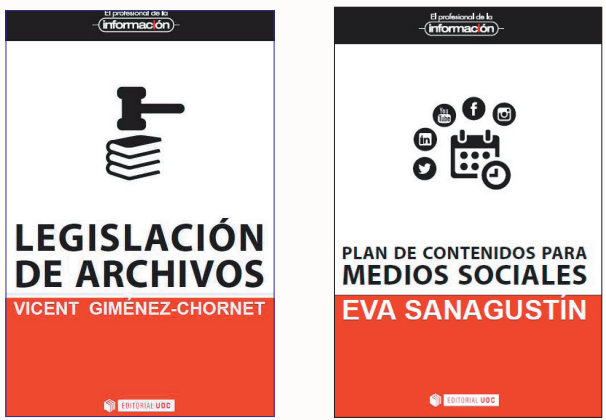

El profesional de la información

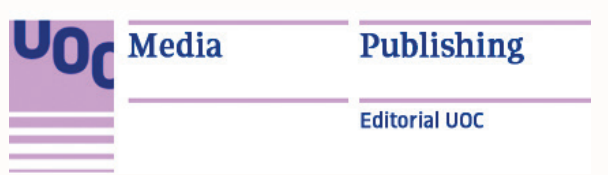

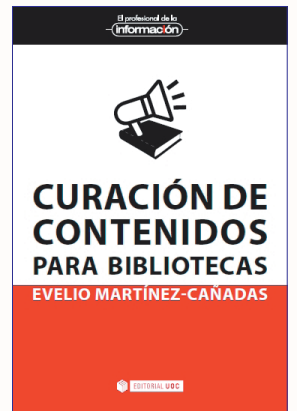
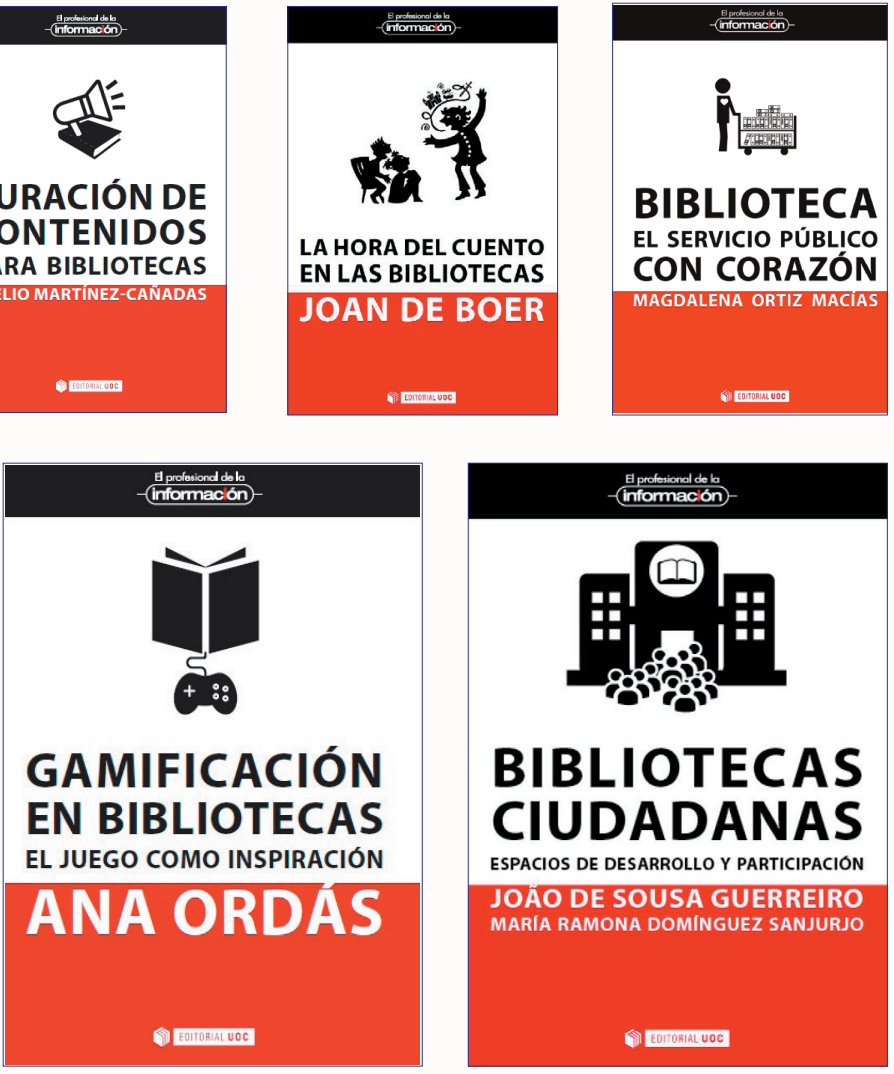

Más información: 